\title{
Cardiac anomalies in children with non-syndromic cleft lip and palate at the Dental Teaching Hospital, Peradeniya, Sri Lanka
}

\author{
*Parakrama Wijekoon ${ }^{1}$, Sunathra Irugal Bandara ${ }^{2}$, Thanuja Herath ${ }^{3}$
}

Sri Lanka Journal of Child Health, 2021; 51(1): 29-33

DOI: http://dx.doi.org/10.4038/sljch.v51i1.9989

\begin{abstract}
Introduction: Cardiac anomalies are the most common congenital abnormalities associated with cleft lip and/or palate, data of which, for Sri Lankan population, are not available.
\end{abstract}

Objectives: To assess the frequency of cardiac anomalies in children with non-syndromic cleft lip and/ or palate at the Dental Teaching Hospital, Peradeniya, Sri Lanka

Method: This was a retrospective cross-sectional study at the Dental Teaching Hospital, Peradeniya Sri Lanka. Records of all children aged 14 years and below with non-syndromic oral clefts, who attended the clinic between January 2018 and January 2019 were studied.

Results: Total number fulfilling inclusion criteria was 150 , of which $52 \%$ were males. Cleft lip with or without cleft palate was found in $96(64 \%)$ and $50(33.3 \%)$ had isolated cleft palate. There were four $(2.7 \%)$ with sub-mucous cleft palate. Cardiac anomalies were found in 59\% comprising 17.3\% with patent foramen ovale (PFO), 16.7\% with ostium secundum atrial septal defect (ASD), 2\% with patent ductus arteriosus (PDA), $1.3 \%$ with tetralogy of Fallot and $14.7 \%$ with other/multiple anomalies. Time gap from birth to initial

\footnotetext{
${ }^{1}$ Consultant Oral \& Maxillofacial Surgeon and Senior Lecturer, Department of Oral \& Maxillofacial Surgery, Faculty of Dental Sciences, University of Peradeniya, Sri Lanka, ${ }^{2}$ Consultant Paediatric Cardiologist, Sirimavo Bandaranayake Specialized Children's Hospital, Peradeniya, Sri Lanka, ${ }^{3}$ Consultant Paediatrician, Division of Pharmacology / Cleft Paediatrician and Senior Lecturer, Faculty of Dental Sciences, University of Peradeniya, Sri Lanka

*Correspondence: pwijekoon@yahoo.com
}

D. https//orcid.org/ 0000-0001-5466-6228

(Received on 25 December 2020: Accepted after revision on 19 February 2021)

The authors declare that there are no conflicts of interest

Personal funding was used for the project.

Open Access Article published under the Creative

Commons Attribution CC-BY (c) (i) License echocardiography was 6 months or less in $65 \%$. Gender or types of clefts were not significantly associated with presence of cardiac anomalies $(\mathrm{p}=0.154 ; \mathrm{p}>0.05)$ and $(\mathrm{p}=0.377 ; \mathrm{p}>0.05)$ respectively. Time gap from birth to initial echocardiography, and detecting cardiac anomalies was significantly associated $(\mathrm{p}=0.027 ; \mathrm{p}<0.05)$.

Conclusions: There was a 59\% frequency of cardiac abnormalities in children with cleft lip and palate. Common cardiac anomalies detected were PFO (17.3\%) and ostium secundum ASD (16.7\%).

(Key words: Cardiac anomaly, Cleft lip and palate, Sri Lanka)

\section{Introduction}

According to the World Health Organisation (WHO), congenital malformations account for 53 per 1000 live births worldwide and 51 per 1000 live births in South East Asia ${ }^{1}$. Cardiac anomalies are the commonest congenital anomalies associated with cleft lip and/or palate ${ }^{2}$. Globally, one in 500700 births has been identified with an oral cleft ${ }^{3}$. A study showed that the highest prevalence of cleft lip and/ or palate was in Asia (1.57 per 1,000 live births) whereas Africa had the lowest prevalence $(0.57 \text { per } 1,000 \text { live births })^{3}$. An overall prevalence of 9.92 per 10,000 was reported between 2000 and 2005 , in a multi-country project in 30 countries $^{4}$.

The incidence of oral clefts in Sri Lanka according to De Alwis A, et al in 2008 was 2.1 per 1000 live births in Anuradhapura ${ }^{5}$, which is higher than the incidence of 0.83 per 1000 live births reported in the study conducted in Central Province of Sri Lanka in the $1980 \mathrm{~s}^{6}$. Asani $\mathrm{M}$, et al found a prevalence of congenital heart defects in $20 \%$ (6/30) among children with cleft in Northern Nigeria of which atrial septal defect (ASD) accounted for three cases ${ }^{7}$. In contrast, another study from Nigeria reported a prevalence of 9.5\% congenital anomalies among patients with oral clefts aged between 1 day and 41 years, of which $1.6 \%$ had congenital heart disease $(\mathrm{CHD})^{8}$. In Taiwan, prevalence of CHD in individuals with oral clefts below the age of 15 was $5.4 \%{ }^{9}$. Also, in a sample of Jordanian cleft patients, $45.5 \%$ were identified as having malformations in the cardiovascular system ${ }^{10}$. In the cleft care centre at the Dental Hospital Peradeniya, every child with a 
cleft is screened for associated CHD clinically and by echocardiography along with investigations for other abnormalities depending on clinical findings. It is useful to assess the magnitude and the pattern of cardiac anomalies in children with clefts in this centre in overall management of cleft lip and palate.

\section{Objectives}

To assess the frequency of cardiac anomalies in children with cleft lip and / or palate attending the Cleft Care Clinic at Dental Teaching Hospital, Peradeniya, Sri Lanka, from January 2018 to November 2019.

\section{Method}

This was a retrospective cross-sectional study carried out at Cleft Care Centre at Dental Teaching Hospital, Peradeniya, Sri Lanka, which treats about 150-200 new oral cleft cases per year. Hospital records and echocardiographic reports of patients were obtained from the Cleft Care Centre, and Sirimavo Bandaranayake Specialized Children's Hospital, Peradeniya. Study population included all children with non-syndromic cleft lip and/or palate, aged 14 years and below attending the Cleft Care Centre who had undergone 2D echocardiography between January 2018 and January 2019. Children over 14 years old, children with syndromic features and children who did not have the initial routine $2 \mathrm{D}$ echocardiography report were excluded.

Ethical issues: Approval was obtained from the Ethics Review Committee of the Faculty of Dental Sciences, University of Peradeniya (ERC/ FDS/ UOP/1/2018/03). Permission was obtained from both Dental Teaching Hospital and Sirimavo Bandaranayake Specialized Children's Hospital, Peradeniya to access medical records. Collected data were protected by allowing only the principal investigator to access data. Being a retrospective study, informed consent was not possible.
Data were extracted using a data extraction sheet developed to collect the data from patient records. Information extracted included socio-demographic characteristics such as gender, age, associated anomalies including types of cleft, cardiac anomalies detected at the initial 2D echocardiographic studies and recommendation of endocarditis prophylaxis, prior to cleft surgery, while excluding information on personal identification.

A descriptive analysis was carried out for all the variables. A composite table was generated comprising frequency and percentages of sociodemographic characteristics as well as cleft and cardiac anomalies. The socio-demographic characteristics, types of cleft, cardiac and other associated anomalies and recommendation of endocarditis prophylaxis were analysed. The association between the presence and type of cardiac anomalies, and types of cleft was tested using Fisher's exact test considering 95\% CI and 0.05 level of significance. Association between cardiac anomalies and gender was also tested and the time gap from birth to initial echocardiography was analysed. Statistical Package for Social Science version 20 was used in data analysis.

\section{Results}

There was a total of 150 children with cleft lip and/or palate, who met the inclusion criteria, had attended the Cleft Care Clinic at the Dental Teaching Hospital, Peradeniya during the study period and had undergone 2D echocardiography. Age range of the study sample was from birth to 14 years.

Table 1 shows the gender of the study population in relation to the type of cleft. There was a higher frequency of cleft lip in males $(61.5 \%)$ and a higher frequency of isolated cleft palate in females (64\%).

Table 1: Gender of the study population in relation to the type of cleft $(n=150)$

\begin{tabular}{|l|c|c|c|}
\hline \multirow{2}{*}{ Type of Cleft } & Male & \multirow{2}{*}{$\begin{array}{c}\text { Total } \\
\text { n }(\%)\end{array}$} \\
\cline { 2 - 3 } & $59(61.5)$ & $37(38.5)$ & $96(64.0)$ \\
\hline Cleft lip with or without cleft palate n (\%) & $18(36.0)$ & $32(64.0)$ & $50(33.3)$ \\
\hline Isolated cleft palate n (\%) & $01(25.0)$ & $03(75.0)$ & $04(02.7)$ \\
\hline Sub-mucous cleft palate n (\%) & $78(52.0)$ & $72(48.0)$ & $150(100.0)$ \\
\hline Total &
\end{tabular}

In the 96 children who had cleft lip with or without cleft palate, $73(76 \%)$ had unilateral cleft lip while $23(24 \%)$ had bilateral cleft lip.

In the study group $108(59 \%)$ had some type of cardiac anomaly and $62(41 \%)$ had a structurally normal heart. The cardiac anomalies found on echocardiography are shown in Figure 1. The common cardiac anomalies were typical patent foramen ovale (PFO) in $26(17.3 \%)$ children and ostium secundum atrial septal defect (ASD) in 25 (16.7\%) children.

The details of the 22 patients categorised as other/ multiple cardiac anomalies are shown in Table 2. 


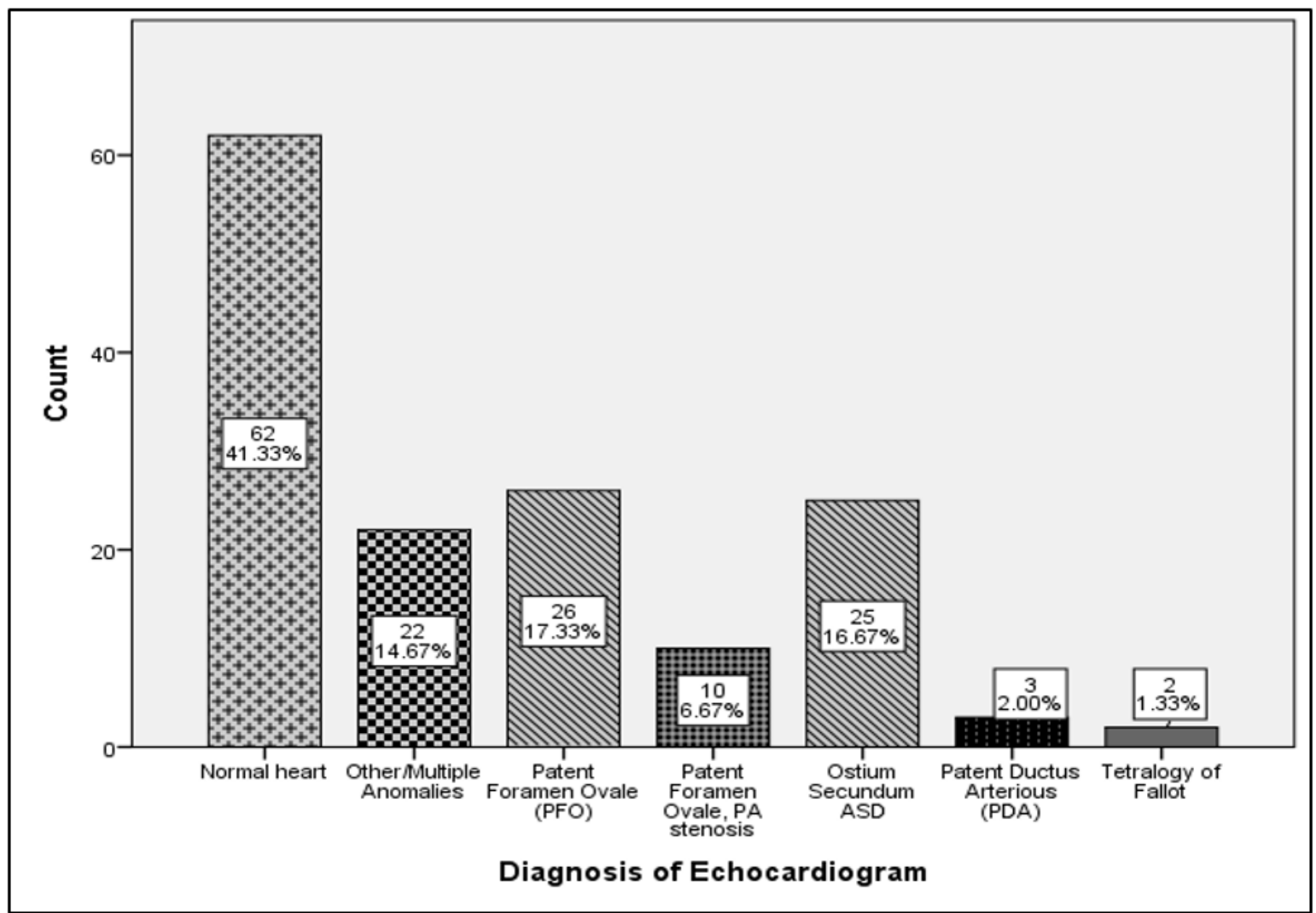

Figure 1: Cardiac anomalies detected on echocardiography

Table 2: Other/multiple cardiac anomalies $(n=22)$

\begin{tabular}{|l|c|}
\hline \multicolumn{1}{|c|}{ Other / Multiple cardiac anomalies } & Frequency (\%) \\
\hline Atrial septal defect (ASD) / Patent foramen ovale (PFO) & $14(63.6)$ \\
\hline PFO + ventricular septal defect (VSD) + patent ductus arteriosus (PDA) & $01(04.6)$ \\
\hline Pulmonary artery stenosis (PAS) + PDA + ASD & $02(09.1)$ \\
\hline VSD + PDA & $01(04.6)$ \\
\hline PAS + VSD + ASD & $01(04.6)$ \\
\hline PDA + ASD & $01(04.6)$ \\
\hline PAS + PFO + ASD & $01(04.6)$ \\
\hline PFO + PDA + ASD & $01(04.6)$ \\
\hline Total & $22(100.0)$ \\
\hline
\end{tabular}

Four patients were found to have mild to moderate pulmonary hypertension. Ten children were recommended for endocarditis prophylaxis. There were no subjects who were recommended any other special interventions with regard to cardiac stability prior to surgery.

Analysis of the results showed that there was no significant association between gender and the echocardiographic diagnosis of cardiac anomalies $(p=0.154 ; p>0.05)$. Also, it was shown that there was no significant association between type of cleft and the cardiac anomaly. $(p=0.377 ; p>0.05)$
Table 3 shows the echocardiographic diagnosis in relation to the time gap from date of birth to date of echocardiography. In the present study, it was found that the time gap from birth to initial echocardiography was 6 months or less in 98 (65\%) children. In $41(27 \%)$ children, it was 3 months or less (Table 3).

There was a significant association between the time gap from birth to date of echocardiography (age of baby at the time of echocardiography), and the frequency of cardiac anomalies diagnosed by 2 D echocardiogram $(p=0.027 ; p<0.05)$. 
Table 3: Echocardiographic diagnosis with time gap from date of birth to date of echocardiography

\begin{tabular}{|c|c|c|c|c|c|c|c|}
\hline \multirow[t]{2}{*}{ Echocardiographic diagnosis } & \multicolumn{7}{|c|}{ Time gap from date of birth to date of echo } \\
\hline & $\begin{array}{c}<1 \\
\text { week }\end{array}$ & $\begin{array}{c}<1 \\
\text { month }\end{array}$ & $\begin{array}{c}1-3 \\
\text { months }\end{array}$ & $\begin{array}{c}4-6 \\
\text { months }\end{array}$ & $\begin{array}{c}7-12 \\
\text { months }\end{array}$ & $\begin{array}{c}>1 \\
\text { year }\end{array}$ & Total \\
\hline Normal Heart & 3 & 3 & 9 & 16 & 14 & 17 & 62 \\
\hline Patent foramen ovale (PFO) & 2 & 5 & 11 & 3 & 4 & 1 & 26 \\
\hline PFO, Pulmonary artery stenosis & 2 & 2 & 5 & 0 & 0 & 1 & 10 \\
\hline Ostium secundum atrial septal defect & 5 & 2 & 7 & 3 & 6 & 2 & 25 \\
\hline Patent Ductus arteriosus (PDA) & 0 & 0 & 2 & 0 & 0 & 1 & 3 \\
\hline Others / Multiple cardiac anomalies & 5 & 2 & 6 & 2 & 2 & 3 & 22 \\
\hline Tetralogy of Fallot & 0 & 0 & 1 & 0 & 0 & 1 & 2 \\
\hline Total & 17 & 16 & 41 & 24 & 26 & 26 & 150 \\
\hline
\end{tabular}

\section{Discussion}

Cleft lip and/ or palate has adverse impacts on appearance, feeding, speech, hearing and long-term psychological wellbeing ${ }^{11}$. They are often associated with other congenital abnormalities including cardiac anomalies ${ }^{11,12}$. Present study investigated the frequency and associations of cardiac anomalies, in a hospital-based sample of children with cleft lip and/or palate. The gender distribution in the study group was almost equal with $52 \%$ males and $48 \%$ females. There was a higher incidence of cleft lip with or without cleft palate among males and a higher incidence of isolated cleft palate among females, is similar to previous studies ${ }^{13}$. Majority of children in present study had PFO followed by ASD and PDA which is different from past studies. Asani M, et al found ASD to be the commonest CHD accounting for $50 \%$ of cases. Similarly, ASD was the commonest anomaly in the study by Rawashdeh MA, et $a l^{10}$. These findings contrast with those of Fakhim SA, et $a l^{14}$ who found VSD and cono-truncal anomalies to be the commonest cardiac deformities in patients with clefts. Absence of a statistically significant association between gender and cardiac anomalies in our study accords with the findings in an Iranian population ${ }^{14}$. Similarly there was no association between types of cleft and cardiac anomalies ${ }^{15}$.

There were no previous studies stating the age at which the echocardiographic diagnosis was made in children with oral clefts. In the cleft centre at Dental Hospital Peradeniya, routine echocardiography is done soon after registration in every child, repeated prior to surgery and thereafter, as recommended by paediatric cardiologist. Early cardiac assessment is done to detect anomalies needing early intervention, before cleft lip is corrected around 3 months of age and cleft palate around 10 months. In present study echocardiography was done within 6 months of birth in $65 \%$ of patients, $27 \%$ being below 3 months. There was a statistically significant association between age of initial echocardiography and frequency of cardiac anomalies.
The majority of anomalies found in the present study were PFOs. The natural history of PFO, with no associated serious structural anomalies, is to undergo spontaneous closure in most children within 6 months of birth, only $25 \%$ persisting into adult life ${ }^{16}$. Although the same was noted in some of the present study group, it could not be included in the analysis due to non-availability of repeat echocardiography reports in the hospital records of all children. Since the majority of echocardiographs in the present study were done at or below the age of 6 months, it is possible that most of the PFOs were detected by early echocardiography before they naturally closed. It is also possible that PFOs persist longer in babies with oral clefts although no treatment was indicated in the majority. The findings of the present study may not be compatible with other studies due to dissimilarities in the age at which the initial echocardiographic examination was done, the age group of the study participants, the non-availability of follow up echocardiographic reports and varied sample size and study design.

\section{Conclusions}

Incidence of cardiac anomalies among children with non-syndromic cleft lip and / or palate attending the Cleft Care Clinic at Dental Teaching Hospital, Peradeniya, Sri Lanka was 59\%. Most frequent anomaly was PFO, followed by ASD. Gender or type of cleft was not significantly associated with the incidence of cardiac anomalies but a statistically significant association was found between the age at which echocardiography was done and presence of cardiac anomalies.

\section{References}

1. WHO. Birth defects in South-east Asia a public health challenge. World Health Organisation Regional Office, South-EastAsia [Internet]. 2013;SEA-CAH-13:6370. Available from:

http://apps.searo.who.int/PDS_DOCS/B49 62.pdf

2. Leite GCP, Ururahy MAG, Bezerra JF, Lima VMGDM, Costa MIF, Freire SSC, et al. Cardiovascular abnormalities in 
patients with oral cleft: A clinicalelectrocardiographic-echocardiographic study. Clinics (Sao Paulo) 2018; 73: e108. https://doi.org/10.6061/clinics/2018/e108

3. Panamonta V, Pradubwong S, Panamonta M, Chowchuen B. Global birth prevalence of orofacial clefts: A systematic review. Journal of the Medical Association of Thailand 2015; 98: S11-21.

4. Mastroiacovo P, Maraschini A, Leoncini E, Mossey P, Bower C, Castilla EE, et al. Prevalence at birth of cleft lip with or without cleft palate: Data from the International Perinatal Database of Typical Oral Clefts (IPDTOC). Cleft Palate-Craniofacial Journal 2011; 48(1): 66-81.

https://doi.org/10.1597/09-217

PMid: 20507242

5. De Alwis A, De Silva K, Bandara W, Gamage T. Prevalence of talipes equinovarus, congenital dislocation of the hip, cleft lip/cleft palate, Down syndrome and neural tube defects among live newborns in Anuradhapura, Sri Lanka. Sri Lanka Journal of Child Health 2008; 36(4): 130.

https://doi.org/10.4038/sljch.v36i4.72

6. Amaratunga ANDS, Chandrasekera A. Incidence of cleft lip and palate in Sri Lanka. Journal of Oral and Maxillofacial Surgery 1989; 47(6): 559-61.

https://doi.org/10.1016/S02782391(89)800 66-7

7. Asani MO, Aliyu I. Pattern of congenital heart defects among children with orofacial clefts in Northern Nigeria. Journal of Cleft Lip Palate and Craniofacial Anomalies 2014; 1(2): 85-7. https://doi.org/10.4103/2348-2125.137895

8. Aimiede OS, Olalere GO, O OA, I SA. Orofacial clefts: Our experience in two suburban health facilities. Dentistry 2013; 3(1): 3-6.

9. Liang CD, Huang SC, Lai JP. A survey of congenital heart disease in patients with oral clefts. Acta Paediatrica Taiwan 1999; 40(6): 414-7.

10. Rawashdeh MA, Jawdat Abu-Hawas B. Congenital associated malformations in a sample of Jordanian patients with cleft lip and palate. Journal of Oral and Maxillofacial Surgery 2008; 66(10): 2035-41.

https://doi.org/10.1016/j.joms.2008.01.009 PMid: 18848099

11. Pereira A V, Fradinho N, Carmo S, De Sousa JM, Rasteiro D, Duarte R, et al. Associated malformations in children with orofacial clefts in Portugal: A 31-year study. Plastic and Reconstructive Surgery - Global Open 2018; 6(2):1-7. https://doi.org/10.1097/GOX.0000000000 001635

PMid: 29616161 PMCid: PMC5865923

12. Shprintzen RJ, Siegel-Sadewitz VL, Amato J, Goldberg RB. Anomalies associated with cleft lip, cleft palate, or both. American Journal of Medical Genetics 1985; 20(4): 585-95. https://doi.org/10.1002/ajmg.1320200404 PMid: 3993684

13. Alhayyan WA, Pan SC, AlQatami FM. Birth prevalence of orofacial clefts in Kuwait from hospital-based registration: Retrospective study. Cleft PalateCraniofacial Journal 2018; 55(10):14505. https://doi.org/10.1177/105566561876605 9

PMid: 29708800

14. Fakhim SA, Shahidi N, Lotfi A. Prevalence of associated anomalies in cleft lip and/or palate patients. Iranian Journal of Otorhinolaryngology 2016; 28(2): 1359.

15. Barbosa MM, Rocha CMG, Katina $\mathrm{T}$, Caldas M, Codorniz A, Medeiros C. Prevalence of congenital heart diseases in oral cleft patients. Pediatric Cardiology 2003; 24(4): 369-74. https://doi.org/10.1007/s00246-002-03359

PMid: 12522651

16. Hampton T, Alsaleem M, Murphy-Lavoie HM. Patent Foramen Ovale. 2020 Sep 15. In: StatPearls [Internet]. Treasure Island (FL): StatPearls Publishing; 2020 Jan-. PMID: 29630203. 